\title{
Journal of Laboratory Physicians (JLP): Success Story
Despite Many Challenges
}

\section{MOTIVATION}

$\int$ y story starts from 1 November 1984 after the tragic assassination of our beloved Prime Minister Mrs. Indira Gandhi. In fact, I was a junior resident in the Department of Orthopedics at Dr. Ram Manohar Lohia Hospital, New Delhi, when I heard news of gunfire at the Prime Minister's House, and the whole hospital was put on alert. The communications in those days were not as quick as are these days and there were no mobile phones. Some injured persons were rushed to casualty, and being in surgical discipline, I happened to be the first person to assist these patients, including the main assassins, Mr. Satwant Singh and Kehar Singh. The next several days saw unforgettable and heart rendering scenes and stories which are out of scope of this editorial. However, I wish to narrate a case that changed my life forever and turned an orthopedic surgeon into an infectious disease specialist. One girl belonging to a Sikh family of six sisters got hospitalized in our unit. Her two sisters were killed brutally in these anti-Sikh riots; she was badly beaten, her pelvic bone and left lower limb bones were badly compound fractured, and above knee amputation was done. She was put under my direct care as I was the junior most resident and I sincerely provided all medical and surgical care to her. Her post-surgical recovery was good and she improved a lot. Unfortunately, after 1 month, our beds were reshuffled and her bed was allotted to my colleague. However, every time during my rounds, her father would ask me for her dressing, but I would helplessly say to him that she was not under my care anymore. She would look at me so desperately and with thousands of hopes, but I was unable to help her. My colleague could not provide the desirable dressing and medical care to her, and in due course of time, her bandages got heavily infected with Pseudomonas, and she finally developed septicemia and died.

\begin{tabular}{|l|l|}
\hline \multicolumn{2}{|c|}{ Access this article online } \\
\hline Quick Response Code: & \\
\hline & \\
\hline
\end{tabular}

Her death made a deep emotional indent on a doctor's personality forever. During my MBBS course, I was the weakest in pathology and microbiology (combined in those days) and I never even dreamt to become a microbiologist as I always loved surgery. Nevertheless, after this episode, I appeared for MD entrance test of Post Graduate Institute of Medical Education and Research, Chandigarh. I opted for an MD in Microbiology and was selected, with a dream of becoming an infectious disease specialist, who can diagnose and treat infectious diseases concomitantly. But when I actually undertook routine laboratory rotations in various laboratories, I realized that microbiology teaching in India was not as I imagined. For one whole year, I was continuously looking for infectious disease course in India, but could not find it anywhere in India. With a heavy heart, I completed my MD, though fortunately, I got an MD thesis topic of my interest, which was on Candida colonization and invasion of gastric ulcers in cimetidine treated patients. During this project, I could treat several patients to my satisfaction and many are still in touch with me.

However, my zeal to develop this discipline in India continued, more so after realizing that our colleagues from medical and surgical discipline look down at the microbiologists and pathologists. The fault is not one sided though. These so-called paramedical departments are dominated by medicos who have chosen to take their life easy. Even though they draw the same salary as their counterparts in so-called clinical departments, their efforts and concerns to the patient's health are not equitable. Most of my colleagues in the microbiology department across India are lazier to reach the department early in the morning by which time a surgeon would have already operated on one or two patients, and they leave early in the evening when others are busy in clinics or taking ward rounds.

Notwithstanding this dichotomy, I continue to struggle to make both the sides come at par. For this, there is an urgent need to start a specialty of infectious diseases. This becomes most desirable in the current scenario wherein India lacks grossly on hospital infection control guidelines, policy on rational use of antibiotics and management of drug resistant bugs. These policies will never succeed if they remain as government policies but need to be embedded in 
our medical curriculum. In this direction, I initiated talks with some like-minded microbiologists, biochemists, pathologists and a few specialists from other disciplines to form Indian Association of Laboratory Physicians (IALP) in 2001. The aim of this association was not only to bring the paramedical disciplines at par with clinical disciplines but also to inculcate a sense of direct responsibility toward patients in the faculties of these departments, commonly known as easy departments, often liked by females and those who do not want to be disturbed at night and on holidays for attending patients.

\section{SUCCESS}

The association started its Journal of Laboratory Medicine (JLM) in 2004, which was published by a lesser-known Pragati Publishing Co., but it faced several problems. These included lack of funds for its publication and quality of manuscripts. Thanks to Dr. VM Katoch, Secretary, Department of Health Research, Government of India, who, after taking over as the President of the IALP, allowed us to look for better publisher and approved seed grant from IALP account to start the journal. He was also kind enough to put forward his views which strengthened my aspirations. ${ }^{[1]}$ Then, Dr. DK Sahu from Medknow Publications approached me in 2008 and offered his services to publish our journal. Interestingly, within few weeks of mutual agreement, we came to know that another journal named Journal of Laboratory Medicine is being published in German and is registered in that country. This led us to change the name of $J L M$ to $J L P$. The first issue of $J L P$ appeared in 2009.

The last two years have been predominantly very satisfying for me as the founder editor of this journal. With the help of Medknow Publications, friends on the editorial board and reviewers who helped in selecting good manuscripts, the journal has bloomed fully. Most satisfying accomplishment for any editor is indexing of the journal. I am very pleased to write that now this journal is indexed in Pub Med and various other indexing services. My next endeavor would be journal's indexing in current contents and high citation rate of our published material. All of us must strive to achieve this goal. Nevertheless, this success has come at a cost. Editing a journal requires lot of time and efforts and sacrificing a good deal of time I used to give to my laboratory and students.

\section{CHALLENGES}

The major handicap for running journals in resourcelimited countries and journals from so-called nonclinical and paramedical branches is lack of funds. Also, for the newer journals, it is really tough to easily get established and attract quality manuscripts. Another embarrassment that I faced as the Editor-in-Chief was plagiarism. Plagiarism is neither new nor unique to our journal, but I did not expect this to happen within the infancy stage of my journal, that too, when one of my senior colleague and good friend was involved in it. It was not just one or two paragraphs or a table but two full articles were plagiarized which fortunately were brought to our notice within 15 days of publication. In the present case, one, Prabhat Ranjan, along with Neelima Ranjan, and DR Arora from Pt. B. D. Sharma Post Graduate Institute of Medical Sciences, Rohtak, and Maharaja Agrasen Medical College, Agroha, Haryana, respectively, had plagiarized two original articles published earlier by others. The first article was titled "An approach to uropathogenic Escherichia coli in urinary tract infections". [2] This article was a ditto copy of an original paper titled "Occurrence and characterisation of uropathogenic Escherichia coli in urinary tract infections" published by Raskha et al. in Indian Journal of Medical Microbiology. ${ }^{[3]}$ The plagiarists had copied this article word-for-word including the number of patients, number of controls, percentage of isolates, headings and sub-headings and even keywords and conclusions. Interestingly, they had dared to cite the original publication in the list of references. The same group of authors had plagiarized another paper titled "Prevalence of Pseudomonas aeruginosa in post-operative wound infection in a referral hospital in Haryana, India". ${ }^{[4]}$ This work was originally published elsewhere as "Pseudomonas aeruginosa isolation in post-operative wound in a referral hospital in Haryana, India" in 2009 by Ruhil et al..$^{[5]}$ from the same department and institution. In this paper too, the plagiarists had copied every word in the abstract and more than $99 \%$ text from the original paper. Unfortunately, the senior author is an assessor of laboratories for the National Accreditation Board for Testing and Calibration Laboratories (NABL). After the matter was brought to our notice by one of the original authors, we had withdrawn both the manuscripts.

Plagiarism literally means the act of appropriating the literary work of another author or expert, whole or in part (more than 40\%), as one's own work. Though plagiarism can occur in any field, plagiarism in medicine is more critical. Plagiarism in medicine has been reported for long and the controversy can be traced as back as 1859. It is notable that in 1964, Lister claimed the use of carbolic acid for the treatment of compound fracture for the first time. But documents prove that this claim was not correct and indeed the carbolic acid was used for dressing the wounds by Cruviehier, Follet and Rigault in 1959, and later on 
for the dressing and treatment of compound fractures in 1960 by Darrican and Petit. ${ }^{[6]}$ In those days there were no copyrights and patent laws. Even then, persons claimed discoveries and inventions for their own fame and name, and often it was unintentional and due to lack of information. However, these days plagiarism is mostly intentional for monitory and career gains.

Intentional authorship plagiarism is seen as a serious crime in academics. Not only publishers, editor and reviewers, but also all academic institutions are duty bound to prevent plagiarism. This objective can be accomplished only if all these institutions become vigilant and also impose heavy penalties on the plagiarists. The penalties should depend on the nature of crime (plagiarism) and be deterrent enough. Unfortunately, India is not yet ready for such corrective measures. This is evident from our letter written to the Directors of both medical institutions and the NABL to take action against the plagiarists, but no action has been taken by any of the organizations. I am optimistic that in future, academic institutions will be proactive and recognize the severity of plagiarism.

\section{REFERENCES}

1. Katoch VM. Recognizing the laboratory physicians. J Lab Physicians 2009;1:1-1.

2. Ranjan PK, Ranjan N, Chakraborty A, Arora DR. An approach to uropathogenic Escherichia coli in urinary tract infections. J Lab Physicians 2010;2:70-3.

3. Raksha R, Srinivasa H, Macaden RS. Occurrence and characterisation of uropathogenic Escherichia coli in urinary tract infections. Indian J Med Microbiol 2003;21:102-7.

4. Ranjan PK, Ranjan N, Bansal SK, Arora DR. Prevalence of Pseudomonas aeruginosa in post-operative wound infection in a Referral Hospital in Haryana, India. J Lab Physicians 2010;2:74-7.

5. Ruhil K, Arora B, Adlakha H. Pseudomonas aeruginosa Isolation of Postoperative Wound in a Referral Hospital in Haryana, India. J Infect Dis Antimicrob Agents 2009;26:43-8.

6. Perrins D. Plagiarism in Medicine. Br Med J 1974;4:106.

\section{Sarman Singh}

Division of Clinical Microbiology, Department of Laboratory Medicine, All India Institute of Medical Sciences, New Delhi, India.

Address for correspondence: Prof. Sarman Singh, E-mail: sarman_singh@yahoo.com 